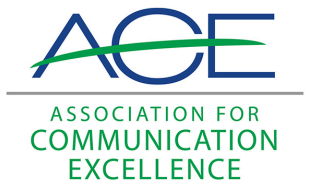

Journal of Applied Communications

\title{
Framing Friction: A Content Analysis Investigating How the CDC Framed Social Media Communication with the Public During the COVID-19 Pandemic
}

\author{
Michaela Kandzer \\ University of Florida \\ Valentina Castano \\ Lauri M. Baker \\ University of Florida
}

See next page for additional authors

Follow this and additional works at: https://newprairiepress.org/jac

Part of the Health Communication Commons, Mass Communication Commons, Organizational Communication Commons, and the Social Media Commons

(c) (1)(2) (2)

This work is licensed under a Creative Commons Attribution-Noncommercial-Share Alike 4.0 License.

\section{Recommended Citation}

Kandzer, Michaela; Castano, Valentina; Baker, Lauri M.; and McLeod-Morin, Ashley (2022) "Framing Friction: A Content Analysis Investigating How the CDC Framed Social Media Communication with the Public During the COVID-19 Pandemic," Journal of Applied Communications: Vol. 106: Iss. 1. https://doi.org/10.4148/1051-0834.2406

This ACE Conference Paper is brought to you for free and open access by New Prairie Press. It has been accepted for inclusion in Journal of Applied Communications by an authorized administrator of New Prairie Press. For more information, please contact cads@k-state.edu. 


\title{
Framing Friction: A Content Analysis Investigating How the CDC Framed Social Media Communication with the Public During the COVID-19 Pandemic
}

\author{
Abstract \\ The novel coronavirus was first discovered in Wuhan, China in December 2019. This zoonotic disease \\ quickly spread through over 100 countries, including the U.S. The World Health Organization (WHO) \\ declared a global health emergency by the end of January 2020. Soon after, many U.S. states issued \\ mandatory stay-at-home orders, which caused adverse effects for agricultural businesses and food \\ supply chains. During this crisis, the Centers for Disease Control and Prevention (CDC) shared information \\ through social media platforms such as Facebook. This study sought to understand how the CDC framed \\ direct communication to the public about issues related to COVID-19 using Facebook videos. Five videos \\ directly related to COVID-19 were selected from the CDC's Facebook page for analysis. A content and \\ framing analysis was used to determine emergent frames and the use of organization-public relationship \\ (OPR) indicators to better understand how a public entity communicates with the public during a \\ pandemic. Emergent frames were community, protecting yourself, encouragement to take action, \\ understanding, and fear. A conversational tone of voice was used in four out of the five videos, and each \\ video demonstrated the use of at least one OPR indicator. Implications from this work reinforce that \\ Facebook videos can be used to communicate the importance of scientific information using \\ conversational voice and OPR indicators. It is recommended that agricultural communicators include OPR \\ indicators in social media videos during other similar zoonotic disease crises. Future research should \\ seek to understand the public's response to this type of scientific communication.
}

\section{Keywords}

zoonotic disease, strategic communication, framing, social media, public relations

\section{Cover Page Footnote/Acknowledgements}

This manuscript was presented at the 2021 National ACE Conference.

\section{Authors}

Michaela Kandzer, Valentina Castano, Lauri M. Baker, and Ashley McLeod-Morin 


\section{Introduction}

COVID-19 emerged in late December 2019 as an infectious disease caused by a newly discovered strand of the coronavirus (World Health Organization [WHO], 2020). COVID-19 is a respiratory illness easily spread among people primarily through respiratory droplets in the air or discharge from the nose when an infected person coughs or sneezes. This disease has a range of effects and symptoms ranging from mild to severe. Vulnerable populations, including the elderly or individuals with underlying or preexisting medical conditions, are at a higher risk for more severe illness or death related to COVID-19.

The spread of COVID-19 is mainly transmitted from person to person. With COVID-19 being a strand of coronavirus, which is commonly seen in bats, at the time of this study, researchers suspected that COVID-19 was tied to a bat that originated in Wuhan, China (Ahmad et al., 2020, Morens et al., 2020). Diseases that spread from animals to humans are defined as zoonotic diseases (Centers for Disease Control and Prevention [CDC], 2017a), and can spread through direct or indirect contact. Zoonotic diseases can be vector-borne, food-borne, or waterborne. New infectious and zoonotic diseases are emerging at alarming rates (Rohr et al., 2019) and pose serious threats to the agricultural industry and food production. These threats directly impact the areas of the agricultural industry that involve animals. To combat these diseases, additional policy implications and research are needed (Rohr et al., 2019).

COVID-19 was first reported by the WHO on January 9, 2020 (The American Journal of Managed Care Staff [AMJC], 2020). Later that month, the United States reported its first confirmed case of COVID-19. On January 31, 2020, the WHO issued a global health emergency. The United States followed suit and declared COVID-19 a public health emergency on February 3, 2020, and a national emergency on March 13, 2020. A few weeks later on March 20, 2020, many states in the U.S. enacted stay-at-home orders, which forced millions of Americans to remain at their home while essential workers, including nurses and farmers, continued to work outside the home to carryout essential functions. The U.S. surpassed a total of 100,000 COVID19 related deaths by May 28, 2020.

The international outbreak of COVID-19 posed serious threats to public health and significantly altered American life, including social, community, and business activities (CDC, 2020a). During the pandemic, individuals were encouraged to protect themselves and others by washing their hands, using alcohol-based hand sanitizer, wearing face masks, avoiding touching their faces, staying at least six feet away from others, and self-quarantining at home (CDC, 2020b; WHO, 2020). These measures brought economies, communities, and American lives to a standstill (AMJC, 2020). Non-essential businesses were forced to shut down, which caused nearly 10 million Americans to become jobless (Taylor, 2020).

\section{About the CDC}

The CDC, a national public health institute in the U.S. that works to protect Americans from threats to national health and safety, played a primary role during the COVID-19 pandemic, including communicating updates related to the disease to the American public (CDC, 2019). The CDC was established on July 1, 1946, in Atlanta, Georgia to combat the spread of malaria (CDC, 2018). The organization evolved and the CDC is now recognized as one of the major operating components of the Department of Health and Human Services (HHS) in the U.S. and is the nation's premier health promotion, prevention, and preparedness agency (CDC, 2018). The CDC was commissioned by the U.S. government in 2004 to detect and mitigate global infectious 
diseases and an initiative to manage the consequences of emerging infectious diseases was established (Christian et al., 2013). Since its commission, the CDC has worked to mitigate and inform the public of national and global health threats, such as Ebola, Zika, mental health illnesses, and COVID-19. The CDC communicated to the public about COVID-19 in several ways, including through its website, Facebook, Twitter, and informational calls (CDC, 2017b).

The CDC utilized its Facebook page during the COVID-19 pandemic to share information with the public regarding COVID-19. The CDC posted videos that answered questions from the public related to the pandemic. These videos covered topics related to cleaning and disinfecting, handwashing, social distancing, wearing face coverings, and at-risk individuals among other topics. The problem under investigation in the current study was to examine how the CDC framed direct communication to the public about issues related to COVID-19 by using the CDC's videos on its Facebook page as a sample of this communication. The larger purpose was to understand what practices would allow a public organization to effectively communicate science with Americans during a time of crisis, which could inform future agricultural communication in a zoonotic disease outbreak and/or Extension communication during future health crises.

\section{Literature Review}

\section{Science \& Health Communication}

Effective science communication with the public is a well-documented challenge in agricultural communication (Lundy et al., 2006; McLeod-Morin et al., 2020; Ruth et al., 2019) particularly in the context of communicating about risk (Palmer et al., 2013; Whaley \& Tucker, 2004). When working to communicate technical health information to the public, Extension educators and scientists face additional challenges in communicating risk while not causing public panic or outrage (Hutchinson, 1999). Effective health and science communication can help Extension more effectively promote behavior changes that result in healthier publics (Gordon, 2002). A general understanding of health and science topics allows people to make relevant decisions regarding their health and the ability to utilize available medical resources (Hazzard, 2019). This need is amplified during a global health crisis, such as the COVID-19 pandemic, when personal health decisions made by individuals can have a profound impact on their health and the health of those around them. The Walsh Center for Rural Health Analysis (2020) describes radio, television, newspaper, internet, and social media as important mediums when disseminating health communication messages to the public. These methods can be used to distribute relevant health information during a pandemic or public health crisis so the public is better equipped to make health decisions for themselves and their loved ones. One challenge to health and science communication is that messages need to reach a broad audience with diverse backgrounds. These audiences likely have varying literacy skills, background knowledge, and interest in the topic discussed. The use of diverse communication strategies can ensure a health and science communication message or campaign reaches a broad audience. Effective health communication occurs when improved health literacy is established by positive communication channels, which are developed through research (Nkanunye \& Obiechina, 2017).

\section{Webinars \& Facebook Live as a Communication Tool}

As different forms of media have continued to develop, both the public and health practitioners have relied heavily on the adaptation to different platforms to be successful. Most 
Americans have reported they receive their news from social media instead of newspapers, with most Americans reporting Facebook as the main platform used to access news, including news about health and science (Shearer, 2019). Specifically, during a crisis, social media can play an important role in an organizational communication strategy (Gibson et al., 2019). Additionally, medical patients have been increasingly reliant on social media platforms to receive information related to their health. Medical patients and health professionals have reported they use social media to increase their knowledge of diseases and to share experiences related to a particular disease and treatment (Antheunis et al., 2013). Facebook Live is a tool used to successfully communicate with patients about disease, diagnosis, and self-care (American Society of Clinical Oncology, 2019). Patients who participated in Facebook Live webinars showed increased control over their healthcare, suggesting the use of evolving social media tools can serve a purpose in communicating health and science topics with the general public.

\section{Framing}

Reese et al. (2001) defined frames as "organizing principles that are socially shared and persistent over time, that work symbolically to meaningfully structure the social world (p. 28)." Frames are used by organizations, individuals, and groups to communicate, assign meaning, and provide a context of understanding to topics or new phenomena, which can be extremely helpful whenever complex issues are being communicated (Hertog \& Mcleod, 2001; Scheufele \& Tewksbury, 2007). Frames often reflect and support major societal institutions and are widely held by individuals within a society.

Studies have been conducted to identify frames used to communicate important topics and issues in agriculture. Lundy et al. (2018) conducted a study to identify and describe frames used when agricultural and health safety issues were communicated in the Florida news media. Researchers identified prominent frames relating to human interest, responsibility, economic consequences, and conflict. Results from this study also indicated that frames carried a lot of weight when shaping individuals' perceptions. These findings are important for agricultural communicators to understand when framing messages related to health and safety in agriculture.

\section{Framing \& COVID-19}

A few studies have been conducted to examine the way varying types of communication related to COVID-19 have been framed. One study conducted by Jordan et al. (2020) sought to compare which frames were the most effective in motivating the public to take part in preventative measures to protect themselves and others from COVID-19. They tested messages that promoted personal threat, public threat, and personal and public threat. The messages focused on personal threat stated how COVID-19 could directly impact the individual. The messages focused on public threat stated how COVID-19 could directly impact the individual's community. Finally, messages focused on personal and public threats stated how COVID-19 could directly impact the individual and their community. Researchers found messages that framed COVID-19 as a public threat were more effective than messages that framed COVID-19 as a personal threat, but no less effective than messages that framed COVID-19 as a personal and public threat (Jordan et al., 2020).

Wicke and Bolognesi (2020) conducted a study that examined the frames used on Twitter when discussing COVID-19. Researchers found that war-related terminology was often used to discuss COVID-19 and thus presented a negative frame. Researchers additionally suggested this 
was in line with frames used by the media and therefore impacted the way individuals framed messages, opinions, and comments related to COVID-19 (Wicke \& Bolognesi, 2020).

\section{Tone of Voice}

In online communication utilizing different tones of voice can influence an organization's relationship with its audience $(\mathrm{Oh} \& \mathrm{Ki}, 2019)$. The two main types of tone of voice used by organizations are human tone of voice and organizational tone of voice. A conversational human tone of voice is a natural tone of voice used to engage listeners and make them feel as if they are having a conversation with an actual human rather than an impersonal organization $(\mathrm{Oh} \& \mathrm{Ki}$, 2019). The impersonal organizational tone of voice is a less authentic tone where listeners feel like they are listening to impersonalized communication. In a recent study, Oh and $\mathrm{Ki}$ (2019) found that utilizing a human tone of voice in organization-public communication can enhance the benefits of communicating with a target audience.

An analysis of Twitter conversations from the 2012-2013 drought in Nebraska was conducted by Wagler and Cannon (2015) to examine the role that educational institutions and organizations played in this conversation. Researchers recommended that educational institutions and organizations get involved in these conversations online to lead and provide fact-based news and information. Findings additionally indicated that the use of a conversational tone of voice would be beneficial and increase brand equity and trust when communicating with the public about a crisis.

Sung and Kim (2018) examined organizational personification and the effect that conversational tone of voice had on relationship quality on social media. Five relationship dimensions, known as organization-public relationship indicators, were used to assess consumers perceptions of two fictitious social media accounts that utilized different tones of voice. Researchers determined that the use of a human tone of voice on social media led consumers to perceive an increased level of relationship investment. This also eventually led consumers to perceive a better-quality relationship with the organization. Researchers recommended that organizations take a personal approach in online communication to build better relationships with the public.

\section{Organization-public Relationships}

An organization's strategic communication and conflict management between stakeholders in its field is a key part of success (Qiu \& Cameron, 2007). During a public health crisis, such as the COVID-19 pandemic, organizations like the CDC need to maintain a positive relationship with the general public while ensuring the organization meets the changing needs of scientists and public leaders both in and out of government (Oiu \& Cameron, 2007). Organization-public relationships (OPR) are described as the interconnection between an organization and its target audience where decisions and actions of one party directly influence the other on an economic, social, political, or cultural level (Thompson, 2014). Ledingham and Bruning (1998) divided the organization-public relationship into dimensions and relationship types. These types are openness, trust, involvement, investments, and commitment. The relationship types are divided into personal, professional, and community (Ledingham \& Bruning, 1998). These OPR indicators can help describe the relationship between an organization and its key public.

The relationship between an organization and its key public was further categorized into six relationship dimensions: control mutuality, satisfaction, trust, exchange relationship, 
communal relationship, and commitment (Hon \& Grunig, 1999). Control mutuality describes the influence an organization and its audience have over each other. The levels of control vary, but these will influence each other to some extent. Satisfaction describes the degree to which an organization and its public approve of each other. This relies on past positive expectations that are reinforced throughout the relationship. Trust between an organization and its key public depends on each party being open to the other. One must trust the other is "fair and just, will do what they say they will do and has the ability to say what they will do" (Hon \& Grunig, 1999, p. 3). Finally, the commitment between the two parties is the belief the relationship is worth the time and energy required to make it work. These guidelines are useful when determining the strength of the relationship between an organization, such as the CDC, and its audience.

The CDC can maintain a relationship with its audience by including positive OPR indicators in its risk communication. In a study regarding OPR indicators and the CDC's communication efforts, positive OPR indicators in risk communication efforts by the CDC were positively associated with an audience's willingness to follow guidelines and instructions from the organization (Chon \& Park, 2019). Additionally, it was found that audiences were more likely to accept information from the CDC during times of crisis if the relationship between both parties was positively maintained during non-crisis times.

\section{Purpose \& Research Questions}

The purpose of this study was to understand how the CDC framed direct communication to the public about issues related to COVID-19 using Facebook videos. The following research questions guided the study to understand:

RQ1. How did the CDC frame advice about preventative actions related to reducing the spread of COVID-19?

RQ2. How did the CDC use tone of voice to frame communication with the public related to COVID-19?

RQ3. How did the CDC frame its relationship with the public using OPR indicators?

\section{Methods}

A case study content analysis approach was used to address the research questions posed in this study. The sample of CDC communication examined in this study was five videos directly related to COVID-19 on the CDC's Facebook page. As social media platforms have continued to expand, individuals have begun to use social media to learn information about their health (Antheunis et al., 2013). Understanding how the CDC frames direct communication to the public may help clarify how the public is guided by an organization during a global health crisis, such as the COVID-19 pandemic, and help other organizations understand how to communicate with target audiences during a similar zoonotic disease outbreak. A content framing analysis was used to the address research questions proposed in this study to determine emergent frames, and to understand the organization-public relationship indicators present in the CDC's relationship with the public.

\section{Sample}

Five videos directly related to COVID-19 were selected from the CDC's Facebook page for analysis. These videos were chosen because they were the only videos to directly address the 
public, which allowed researchers to examine frames used to discuss COVID-19. Videos that directly addressed the public, included a speaker looking into the camera and speaking into the camera. Videos that were cartoons or did not feature a speaker addressing the public, were removed from the sample. One video was presented as a Facebook Live webinar, while the rest were prerecorded. Researchers retrieved direct links from Facebook to each video. Additionally, these videos were chosen due to their high level of reach and audience engagement, as each video had over 500 comments and 1,000 likes or reactions at the time of this study (Table 1). The dates of when these videos were posted ranged from April 8 to June 24, 2020. These were the only videos related to COVID-19 posted by the CDC during this time frame. Videos posted after June 24, 2020 were either not related to COVID-19, not informational, or had a low level of engagement. Data were collected on October 28, 2020.

\section{Table 1}

Units of Analysis for Videos from the CDC Facebook Page During The COVID-19 Pandemic $(n=5)$

\begin{tabular}{|c|c|c|c|c|c|}
\hline Video Title & $\begin{array}{l}\text { Video } \\
\text { Length }\end{array}$ & $\begin{array}{l}\text { Number of } \\
\text { Views }\end{array}$ & $\begin{array}{l}\text { Number of } \\
\text { Reactions }\end{array}$ & $\begin{array}{l}\text { Number of } \\
\text { Comments }\end{array}$ & Date Posted \\
\hline $\begin{array}{c}\text { Can COVID-19 } \\
\text { last on surfaces } \\
\text { and in the air? }\end{array}$ & $1: 13$ & 430,500 & 9,300 & 1,000 & $\begin{array}{l}\text { April 8, } \\
2020\end{array}$ \\
\hline $\begin{array}{l}\text { Can ibuprofen } \\
\text { make COVID- } \\
19 \text { worse? }\end{array}$ & $1: 08$ & 309,100 & 6,700 & 997 & $\begin{array}{l}\text { April 10, } \\
2020\end{array}$ \\
\hline $\begin{array}{l}\text { Can you catch } \\
\text { COVID-19 via } \\
\text { stool? }\end{array}$ & $1: 05$ & 197,000 & 3,600 & 533 & $\begin{array}{l}\text { April 13, } \\
2020\end{array}$ \\
\hline $\begin{array}{l}\text { COVID-19: Are } \\
\text { You at Higher } \\
\text { Risk for Severe } \\
\text { Illness? }\end{array}$ & $2: 23$ & 300,300 & 20,000 & 1,000 & $\begin{array}{l}\text { April 23, } \\
2020\end{array}$ \\
\hline $\begin{array}{l}\text { COVID-19 } \\
\text { Questions } \\
\text { Answered }\end{array}$ & $60: 11$ & 220,400 & 2,700 & 4,900 & $\begin{array}{l}\text { June 24, } \\
2020\end{array}$ \\
\hline
\end{tabular}

\section{Data Analysis}

Two coders analyzed the data in this study. Both coders were graduate students studying agricultural communication with a focus in science communication. The primary coder watched each video multiple times and developed a coding sheet. The coding sheet was used as a guide through the analysis and decision-making process. The coding sheet included questions related to the title of the video, length of the video, number of video views, reactions and comments, the speaker in the video, the topic of the video, and emerging frames (RQ 1-2). Emerging frames 
were identified using Glaser's (1965) constant comparative method. Pre-determined, a priori coding was also used in analysis (RQ 3). A priori coding is used when researchers have codes developed ahead of time based on a theoretical framework. In the case of this study, codes were derived from the OPR theory (Thompson, 2014; Hon \& Grunig, 1999) and were based on previous literature (Hon \& Grunig, 1999; Ki \& Hon, 2007). These codes included: control mutuality, trust, satisfaction, commitment, exchange relationship, and communal relationship. Control mutuality is defined as the level of agreement from each side on who has the influential power on one another (Hon \& Grunig, 1999). Distribution of power is typically negotiated and understood by both parties in a stable relationship (Ki \& Hon, 2007). As an OPR indicator, trust refers to the degree of confidence and openness between parties (Hon \& Grunig, 1999). Trust considers three main concepts, including integrity, dependability, and competence. Satisfaction is defined as the level of favorability each party has towards the other. A relationship that is satisfying results in more benefits than costs (Ki \& Hon, 2007). Commitment is the "extent to which each party believes and feels that the relationship is worth spending energy to maintain and promote" (Hon \& Grunig, 1999, p. 3). An exchange relationship is defined as one group providing benefits to the other group with the only reason in mind that the other group has previously contributed benefits or is anticipated to provide benefits in the future (Hon \& Grunig, 1999). A communal relationship refers to the benefits exchanged between groups out of concern for the other's wellbeing (Hon \& Grunig, 1999). Communal relationships are an important indicator of public relations since communal relationships prioritize the public's interest, rather than just participating in a relationship for the organization's own benefit. Videos were coded using these OPR frames to understand the CDC's relationship with the public. Coders used a 3point scale that ranged from not present to strongly present to rank how present each OPR indicator was in each video. If the OPR indicator was present zero times, the video was ranked not present. If the OPR indicator was present one to three times, the video was ranked moderately present. If the OPR indicator was present more than three times, the video was ranked strong. Researchers opted to use a 3-point scale to have a better understanding of how many times each OPR indicator was present in each video. A codebook was developed according to recommendations by Krippendorff (2013) and Riffe et al. (2019) to define the coding protocol and further guide the coders through the analysis and decision-making process.

The primary and secondary coders worked together and established interrater reliability through protocol training (Dooley, 2001). To ensure reliability, an official reliability analysis was conducted where both coders analyzed one video (20\%) of the sample. Cohen's kappa was calculated for each study variable: tone of voice $(K=.50)$ and OPR frames $(K=.72)$. The combined average kappa value was considered reliable at .61, as a kappa of $0.61-0.80$ is considered substantial (Krippendorff, 2013; McHue, 2012; Riffe et al., 2019). Coders reanalyzed the study codebook after tone of voice reliability was found to be low at .50. The coding protocol was revisited and discussed between coders for clarity. The reliability analysis was then conducted once more, and the tone of voice variable was found to be more reliable $(K=1.00)$, thereby raising the overall study kappa to .86 .

After reliability was established, the coders split up the rest of the sample and coded the videos independently. Coders reconvened and discussed coding decisions to further ensure the reliable interpretation of data (Yin, 2012). NVivo ${ }^{\circledR}$ was used to code and analyze the data.

\section{Limitations}


This study is limited by a small sample size, which is common in case study approaches. Results of this study cannot be generalized, but the findings could be transferable to other organizations with similar characteristics. This study is also limited by the specific zoonotic disease crisis of COVID-19 and what scientific information was available at this time. It is possible that recommendations made by the $\mathrm{CDC}$ within these videos may be different when more is known about COVID-19.

\section{Findings}

\section{Research Question One: How Did the CDC Frame Advice About Preventative Actions Related to Reducing the Spread Of COVID-19?}

Frames emerged from the advice about preventative actions related to reducing the spread of COVID-19 presented in the CDC's interview, question, and answer-style videos on the organization's Facebook page. Emergent frames that were the most salient were community, protecting yourself, encouragement to take action, and understanding. Another frame that emerged but was not as prominent was fear.

\section{Community}

The frame of community emerged with statements that encouraged listeners to protect others by participating in preventative actions to help reduce the spread of COVID-19. This included actions like wearing a cloth face covering, staying home, social distancing, etc. Statements like "cloth face coverings are meant to protect others from the respiratory droplets that you produce," and "protecting...others by staying home is important," indicated a frame of community. Speakers also made statements like "don't forget to maintain social distancing so you don't infect other people," and "using touchless payment options is also great for both the employees, as well as the customers," which further indicated a frame of community.

\section{Protecting Yourself}

The frame of protecting yourself emerged with statements related to wearing a face covering, social distancing, frequent hand washing, avoiding travel, and using disinfectants to protect oneself from contracting COVID-19. Statements like "keep yourself and your children six feet apart or more from others," and "reduce risk by going to the store when there are fewer people there," indicated a frame of protecting yourself. Speakers also made statements like "avoid all cruises and nonessential travel," and "it's really critical that if the cloth face covering cannot be worn for any of those reasons, that those other protective measures... are really important to keep in mind," which further indicated a frame of protecting yourself.

\section{Understanding}

The frame of understanding emerged with statements that indicated a level of understanding about the practicality of following all of the best practices related to staying safe from COVID-19. Additionally, statements that showed a level of care for the difficulty of coping with COVID-19 were coded for understanding. Statements like "wearing a cloth face covering may not always be possible," and "hearing about the pandemic over and over can be upsetting, and it can impact our mental health. So, it's also important...to take time to unwind," indicated a frame of understanding. Speakers also made statements like "[COVID-19] certainly can affect how we relate to others," and "social distancing measures might be difficult to maintain," which further indicated a frame of understanding. 


\section{Encouragement to Take Action}

The frame of encouragement to take action emerged with statements that motivated listeners to take action to stay safe from COVID-19. Statements like "remember to frequently wash your hands," and "as much as possible, keep that physical distance," indicated a frame of encouragement to take action. Speakers also made statements like "take action to reduce your risk of getting sick," and "to learn more visit CDC.gov/COVID-19," which further indicated a frame of encouragement to take action.

\section{Fear}

Lastly, the frame of fear emerged in the videos whenever the speaker made statements related to the risk and severity of COVID-19. One speaker stated that "the more closely you interact with others, and then the longer that interaction is with other people, the higher the risk of COVID-19 exposure or spread." Additionally, a fear frame was indicated in statements like "there's no way to ensure zero risk of infection," and "call 911 if you have emergency warning signs."

\section{Research Question Two: How did the CDC use Tone of Voice to Frame Communication with the Public Related to COVID-19?}

Frames related to tone of voice were coded for either human or organizational tone of voice. Four out of five videos utilized a human tone of voice. One video utilized an organizational tone of voice.

\section{Human Tone of Voice}

The four videos that utilized a human tone of voice introduced the speaker at the beginning of the video and made relational statements like "let's work together to keep each other healthy," "taking care of ourselves is important," "knowing your own level of risk is really important," and "let me tell you what we know." Additionally, videos that utilized a human tone of voice encouraged two-way communication between the organization and the public.

\section{Organizational and Impersonal Tone of Voice}

In the video that used organizational and impersonal tone of voice, the speaker did not introduce herself to listeners. The speaker in this video also spoke more robotically. No relational statements were made in this video. Statements made by this speaker were more stoic. For example, "older adults and people of any age who have underlying medical conditions may be at higher risk of severe complications from COVID-19," and "call 911 if you have emergency warning signs including difficulty breathing...or blueish lips."

\section{Research Question Three: How Did the CDC Frame Its Relationship with The Public Using OPR Indicators?}

OPR indicators were present in every video. The most prevalent OPR indicators identified were trust and communal relationship. Trust was indicated by statements showing that the CDC was actively conducting research and consulting scientists, doctors, and colleagues to ensure the deliverance of accurate and truthful information, and by speakers stating their name and work title. Evidence of a communal relationship was indicated by statements that asked 
listeners to work together to prevent the spread and transmission of COVID-19. Satisfaction as an OPR indicator was not identified in any of the videos.

\section{Trust}

The OPR indicator, trust, emerged with statements that indicated a level of confidence and openness between the CDC and the public. Statements that indicated an effort to demonstrate trust were coded for trust. Statements like "we review the literature regularly and speak to collogues, I'm John Anderton...representing CDC's Emergency Partners Information Connection," and "Dr. Sarah Lee... is the team lead for the Research, Application and Evaluation Team with the School Health Branch in the Division of Population Health here at CDC," indicated trust. Five videos were coded for moderately present, indicating that the trust indicator was somewhat present in five the videos.

\section{Communal relationship}

The OPR indicator, communal relationship, emerged with statements that indicated an exchange of benefits between groups out of concern for the other's wellbeing. Statements that indicated an effort to prioritize the public's interest, rather than the organizations were coded for communal relationship. Statements like "let's work together, my cloth face-covering protects you and yours protects me, helping each other," and "let's work together to keep ourselves healthy, our families healthy and our communities healthy," indicated a communal relationship. Four videos were coded for moderately present, and one video was coded for strong, indicating that the communal relationship indicator was present in five the videos.

\section{Commitment}

The OPR indicator, commitment, refers to extent to which both parties believes that a relationship is worth maintaining and promoting. Statements that indicated an effort to facilitate and maintain a relationship were coded for commitment. Statements like "we are going to continue to monitor this situation, and as things change, we'll tell you," and "these studies are important, and we are going to continue doing them," indicated commitment. Two videos were coded for not at all present, two videos were coded for moderately present, and one video was coded for strong, indicating that the communal relationship indicator was present in four the videos.

\section{Exchange relationship}

The OPR indicator, exchange relationship, emerged with statements that indicated one group provided benefits to the other group with the only reason in mind that the other group has previously contributed benefits or is anticipated to provide benefits in the future (Hon \& Grunig, 1999). Statements that indicated this type of exchange were coded for exchange relationship. Statements like "and as we learn more information about what this means for you and your home, we will keep you informed," and "there are things that you can be doing," indicated an exchange relationship. Two videos were coded for not at all present, two videos were coded for moderately present, and one video was coded for strong, which indicated that the exchange relationship indicator was only present in three videos. 


\section{Control mutuality}

The OPR indicator, control mutuality, emerged when statements indicated a level of agreement from each side on who has the influential power on one another. Statements that indicated a distribution of power were coded for control mutuality. Statements like "we've been getting a lot of questions," indicated commitment. Four videos were coded for not at all present, and one videos was coded for moderately present, indicating that the control mutuality indicator was present in one video.

\section{Satisfaction}

The OPR indicator, satisfaction, emerged with statements that showed a level of favorability that each party has towards the other. Satisfaction should indicate that the relationship results in more benefits than costs (Ki \& Hon, 2007). Satisfaction was not present in any of the videos included in the sample.

\section{Discussion/Conclusions}

The findings of this study offer understanding into the way a public-facing organization communicates with the public using online communication during a zoonotic disease pandemic. Specifically, this work reinforces that social media videos can be used to communicate the importance of scientific information using conversational voice and OPR indicators during a pandemic. The CDC framed communication about preventative actions related to reducing the spread of COVID-19 using frames of community, protecting yourself, encouragement to take action, understanding, and fear. This aligns with a previous research study that reported that frames were used by the CDC to communicate, assign meaning, and provide a context of understanding to topics related to COVID-19 (Reese et al., 2001). This study also aligned with previous research conducted by Jordan et al. (2020), which stated that frames related to public and personal threat are used in communication to motivate the public to take part in preventative actions. This research differs from previous research conducted by Wicke and Bolognesi (2020), where war-related terminology was not used to describe COVID-19. Most of the frames used by CDC were positive, however, the less prominent frame of fear was negative. Fear can lead to public panic or outrage and has been recognized as something Extension communicators should avoid when communicating risk to the public (Hutchinson, 1999).

The CDC used a human tone of voice in the majority of its communication. This is positive and may improve the CDC's relationship with its audience. This aligns with previous work by $\mathrm{Oh}$ and $\mathrm{Ki}$ (2019) in that utilizing a human tone of voice rather than an organizational tone of voice can enhance the benefits of communicating with the public. However, all communication from an organization should be consistent, so that the relationship with the public is consistent. Thus, it is concerning that one CDC video used an organizational voice, which is less likely to build a relationship and connect with members of the public.

Each video demonstrated the use of at least one OPR indicator. The most used OPR indicator was trust. Satisfaction was the least used indicator and did not appear in any videos. This may indicate an unstable relationship between the CDC and the public. This aligns with previous work on OPR indicators and crisis communication by Oiu and Cameron (2007). For organizations to maintain a positive relationship with the general public, OPR indicators must be present. 


\section{Recommendations}

Results from this study can be used to inform the work of science and health communicators both at the CDC and in Extension and academic settings. Like the CDC, Extension is often looked to as a local source of research-based information and could therefore learn lessons from the $\mathrm{CDC}$ on communicating this type of information. Principles of organizational communication can be applied from industry to industry. The data analyzed suggests there may be room for improvement within the current communication strategies of the CDC. Future communication efforts should continue to include calls to action and ensure a human tone of voice is used to convey messages. In the future, the CDC should consider the OPR framework in all external communications to continuously build and maintain a relationship with the public. This will ensure that during a time of crisis, important OPR indicators such as trust are already established. By having an established relationship with the public, science communicators and the CDC will be better able to provide recommendations during a time of crisis. This will facilitate the spread of accurate information because the public will be more receptive to messages from the CDC, especially if important factors such as satisfaction and trust are already established.

Agricultural communicators, particularly Extension communicators focused on science and health communication, can learn from this work when they frame public-facing, researchbased videos about health and science communication. In cases where agricultural or Extension communicators are communicating about zoonotic diseases, fear frames should be avoided (Wicke \& Bolognesi, 2020), and frames that emphasize the public threat should be used (Jordan et al., 2020). Communicators should prioritize incorporating a human tone of voice to foster a relationship with various audiences (Oh \& Ki, 2019). These data show it is possible to include OPR indicators in Facebook videos when communicating about a public health crisis related to a zoonotic disease. Using these OPR indicators may allow for effective risk communication and a reduction in public outrage as recommended for Extension communicators (Hutchinson, 1999). Agricultural communicators can and should include OPR indicators in social media videos during other similar zoonotic disease crises to build trust with the public while sharing accurate, scientific information.

Future research should be conducted to further examine how the CDC uses other types of media to communicate with and educate the public on COVID-19. It would be of additional interest to examine how Extension could use Facebook Live videos and webinars to inform the public about research-based information, and how their usage would compare to the CDC. It is recommended future research explore the OPR between the CDC and the public to determine how the relationship is reflected across COVID-19-related communication efforts as a whole. Moreover, research should be done to determine the response of the public to the CDC's Facebook videos to understand the effect of the communication and OPR indicators on the public's relationship with the CDC.

\section{References}

Ahmad, T., Khan, M., Haroon, Musa, T. H., Nasir, S., Hui, J., Bonilla-Aldana, D. K., \& Rodriguez-Morales, A. J. (2020). COVID-19: Zoonotic aspects. Travel Medicine and Infectious Disease. 36(2020), 1477-8939. https://doi.org/10.1016/j.tmaid.2020.101607

Ahmed, W., Bath, P., Sbaffi, L., \& Demartini, G. (2019). Novel insights into 
views towards H1N1 during the 2009 pandemic: A thematic analysis of Twitter data. Health Information and Libraries Journal, 36(1), 60-72. https://doi.org/10.1111/hir.12247

Antheunis, M., Tates, K., \& Nieboer, T. (2013). Patients' and health professionals' use of social media in health care: Motives, barriers and expectations. Patient Education and Counseling. 92(3), 426-431. https://doi.org/10.1016/j.pec.2013.06.020

Centers for Disease Control and Prevention. (2017a, July 17). Zoonotic diseases. https://www.cdc.gov/onehealth/basics/zoonotic-diseases.html

Centers for Disease Control and Prevention. (2017b, November 1). CDC's communication principles. https://www.cdc.gov/about/organization/communication-principles.html

Centers for Disease Control and Prevention. (2018, December 4). Our history - Our story. https://www.cdc.gov/about/history/index.html

Centers for Disease Control and Prevention. (2019, May 13). Mission, role and pledge. https://www.cdc.gov/about/organization/mission.htm

Centers for Disease Control and Prevention. (2020a, June 22). Your COVID-19 questions answered: Daily life, social interaction, returning to work, and more. https://emergency.cdc.gov/epic/learn/2020/webinar_20200624.asp

Centersb for Disease Control and Prevention. (2020b, September 11). How to protect yourself and others. https://www.cdc.gov/coronavirus/2019-ncov/prevent-gettingsick/prevention.html

Centers for Disease Control and Prevention. (2013, April 26). CDC SARS response yimeline. https://www.cdc.gov/about/history/sars/timeline.htm

Christian, K. A., Ijaz, K., Dowell, S. F., Chow, C. C., Chitale, R. A., Bresee, J. S., Mintz, E., Pallansch, M. A., Wassilak, S., McCray, E., \& Arthur, R. R. (2013). What we are watching-five top global infectious disease threats, 2012: A perspective from CDC's global disease detection operations center. Emerging Health Threats Journal, 6(1), 1-8. https://doi.org/10.3402/ehtj.v6i0.20632

Chon, M. \& Park, H. (2019). Predicting public support for government actions in a public health crisis: Testing fear, organization-public relationship, and behavioral intention in the framework of the situational theory of problem solving. Journal of Health Communication, 34(1), 1-11. https://doi.org/10.1080/10410236.2019.1700439

Nkanunye, C. \& Obiechina, G. (2017). Health communication strategies as gateway to effective health promotion and well-being. The Journal of Medical Research and Health Education, 1(3), 1-4.

Dooley, D. (2001). Social research methods (4 ${ }^{\text {th }}$ ed.). Prentice Hall.

Dunn, P. \& Hazzard, E. (2019). Technology approaches to digital health literacy. International Journal of Cardiology, 293(2019), 294-296. https://doi.org/10.1016/j.ijcard.2019.06.039

Gibson, C., Irlbeck, E., Meyers, C., Akers, C., \& Price, P. (2019). An investigation of agricultural crisis communications via social media. Journal of Applied Communications, 103(4), 1-19. https://doi.org/10.4148/1051-0834.2279

Glaser, B. (1965). The constant comparative method of qualitative analysis. Social Problems, 12(4), 436-445. https://doi.org/10.2307/798843

Gordon, J. (2002). Beyond knowledge: Guidelines for effective health promotion messages. Journal of Extension, 40(3). https://www.joe.org/joe/2002december/a7.php

Hertog, J. \& Mcleod, D. M. (2001). A multiperspectival approach to framing analysis: A field 
guide (1st ed.). Framing Public Life: Perspectives on Media and Our Understanding of the Social World, 139-161. https://doi.org/10.4324/9781410605689

Hon, L. \& Grunig, J. (1999). Guidelines for measuring relationships in public relations. www.instituteforpr.org

Hutchinson, S. (1999). Effective use of risk communication strategies for health \& safety educational materials. Journal of Extension, 37(5). https://www.joe.org/joe/1999october/a1.php

Ledingham, J. A. \& Bruning, S. D. (1998). Organization-public relationships and consumer satisfaction: The role of relationships in the satisfaction mix. Communication Research Reports, 198-208. https://doi.org/10.1080/08824099809362114

Lundy, L., Ruth, A., Telg, R., \& Irani, T. (2006). It takes two: Public understanding of agricultural science and agricultural scientists' understanding of the public. Journal of Applied Communications, 90(1), 1-14. https://doi.org/10.4148/1051-0834.1290

Jenkins, E., Ilicic, J., Barklamb, A., \& McCaffrey, T. (2020). Assessing the credibility and authenticity of social media content for applications in health communication. JMIR Publications, 22(7), 1-15. https://doi.org/10.2196/17296

Jordan, J., Yoeli, E., \& Rand, D. (2020). Don't get it or don't spread it? Comparing selfinterested versus prosocial motivations for COVID-19 prevention behaviors. https://doi.org/10.31234/osf.io/yuq7x

Ki, E. J. \& Hon, L. C. (2007). Testing the linkages among the organization-public relationship and attitude and behavioral intentions. Journal of Public Relations Research, 19(1), 1-23. https://doi.org/10.1080/10627260709336593

Kim, H. \& Xie, B. (2017). Health literacy in the eHealth era: A systematic review of the literature. Patient Education and Counseling, 6(2017), 1073-1082. https://doi.org/10.1016/j.pec.2017.01.015

Krippendorff, K. (2013). Content analysis: An introduction to its methodology. SAGE.

LeDuc, J. W. \& Barry, A. M. (2004, November 10). SARS, the first pandemic of the 21st century. Emerging Infectious Diseases, 10(11), 1-2. https://doi.org/10.3201/eid1011.040797_02

Lundy, L. K., Rogers-Randolph, T. M., Lindsey, A. B., Hurdle, C., Ryan, H., Telg, R. W., \& Irani, T. (2018). Analyzing media coverage of agricultural health and safety issues. Journal of Applied Communications, 102(4). https://doi.org/10.4148/1051-0834.2222

McHue, M. (2012). Interrater reliability: The kappa statistic. Journal of Biochem Med, 22(3), 276-282.

McLeod-Morin, A., Telg, R., \& Rumble, J. (2020). Describing interdisciplinary agricultural research center directors' perceptions of science communication through goals and beliefs. Journal of Applied Communications, 104(1), 1-16. https://doi.org/10.4148/1051$\underline{0834.2300}$

Morens, D., Breman, J., Calisher, C., Doherty, P., Hahn, B., Keusch, G., Kramer, L., LeDuc, J, Monath, T., \& Taubenberger, J. (2020). The origin of covid-19 and why it matters. The American Society of Tropical Medicine and Hygiene, 10(3), 955-959. https://doi.org/10.4269/ajtmh.20-0849

Nielsen-Bohlman, L., Panzer, A., \& Kindig, D. (2004). Health Literacy. National Academies Press. 
Palmer, A., Irlbeck, E., Meyers, C., \& Chambers, T. (2013). A case study of the risk and crisis communications used in the 2008 salmonella outbreak. Journal of Applied Communications, 97(1), 38-49. https://doi.org/10.4148/1051-0834.1102

Parker, R. \& Ratzan, S. C., (2010). Health literacy: A second decade of distinction for Americans. Journal of Health Communication, 12(2010), 20-33. https://doi.org/10.1080/10810730.2010.501094

Qiu, Q. \& Cameron, G., (2007). A public relations perspective to manage conflict in a public health crisis. Journal of Dispute Resolution, 1(15), 1-18. https://scholarship.law.missouri.edu/jdr/vol2007/iss1/15

Reese, S., Gandy, O., \& Grant, A. (2001). Framing public life: Perspectives on media and our understanding of the social world. Lawrence Erlbaum Associates, Inc.

Riffe, D., Lacy, S., \& Fico, F. (2019). Analyzing media messages: Using quantitative content analysis in research $\left(4^{\text {th }} \mathrm{ed}\right)$. Taylor \& Francis.

Rohr, J. R., Barrett, C. B., Civitello, D. J., Craft, M. E., Delius, B., DeLeo, G. A., Hudson, P. J., Jouanard, N., Nguyen, K. H., Ostfeld, R. S., Remais, J. V., Riveau, G., Sokolow, S. H., \& Tilman, D. (2019). Emerging human infectious diseases and the links to global food production. Nature Sustainability, 2(6), 445-456. https://doi.org/10.1038/s41893-0190293-3

Ruth, A. M., Eubanks, E. E., \& Telg, R. (2005). Framing of mad cow media coverage. Journal of Applied Communications, 89(4). https://doi.org/10.4148/1051-0834.1312

Ruth, T., Rumble, J., Galindo-Gonzalez, S., Lundy, L., Carter, H., \& Folta, K. (2019). Can anyone hear us? An exploration of echo chambers at a land-grant university. Journal of Applied Communications, 103(2), 1-22. https://doi.org/10.4148/1051-0834.2242

Shearer, E. (2019, December 10). Social media outpaces print newspapers in the U.S. as a news source. https://www.pewresearch.org/fact-tank/2018/12/10/social-media-outpaces-printnewspapers-in-the-u-s-as-a-news-source/

Scheufele, D. A. \& Tewksbury, D. (2007). Framing, agenda setting, and priming: The evolution of three media effects models. Journal of Communications, 57(1). https://doi.org/10.1111/j.0021-9916.2007.00326.x

Sung, K., Kim, S. (2018). Do organizational personification and personality matter? The effect of interaction and conversational tone on relationship quality in social media. International Journal of Business Communication, 25(1). https://doi.org/10.1177/2329488418796631

Tabri, N., Hollingshead, S. J., \& Wohl, M. J. A. (2020). Framing COVID-19 as an existential threat predicts anxious arousal and prejudice towards Chinese people. Unpublished manuscript, Department of Psychology, Carleton University. https://doi.org/10.31234/osf.io/mpbtr

Taylor, D. B. (2020, December 28). How the coronavirus pandemic unfolded: A timeline. New York Times. https://www.nytimes.com/article/coronavirus-timeline.html

The American Journal of Managed Care Staff. (2020, July 3). A timeline of COVID-19 developments in 2020. The American Journal of Managed Care. https://www.ajmc.com/view/a-timeline-of-covid19-developments-in-2020

Thompson, T. (2014). Organization Public Relations Theory, Encyclopedia of Health Communication, SAGE Publications, Inc., Oct 2014. Wagler, A., Cannon, K. (2015). Exploring ways social media data inform public issues communication: An analysis of Twitter conversation during the 2012-2013 drought in 
Nebraska. Journal of Applied Communications, 99(2), 44-60. https://doi.org/ 10.4148/1051-0834.1047

Walsh Center for Rural Health Analysis. (2020). Social Determinants of Health in Rural Communities Toolkit. https://www.ruralhealthinfo.org/toolkits/sdoh

Whaley, S. \& Tucker, M. (2004). The influence of perceived food risk and source trust on media system dependency. Journal of Applied Communications, 88(1), 9-27. https://doi.org/10.4148/1051-0834.1315

Wicke, P. \& Bolognesi, M. M. (2020). Framing COVID-19: How we conceptualize and discuss the pandemic on Twitter. Plos One, 15(9), 1-24. https://doi.org/10.1371/journal.pone.0240010

World Health Organization. (2020). Coronavirus. https://www.who.int/healthtopics/coronavirus\#tab=tab_1

World Health Organization. (2003, August 15). Summary table of SARS cases by country, 1 November 2002 - 7 August 2003. https://www.who.int/csr/sars/country/2003_08_15/en/ Yin, R. (2012). Applications of case study research. Sage Publications.

Zhao, X. (2020). Health communication campaigns: A brief introduction and call for dialogue. International Journal of Nursing Sciences, 7(2020), 11-15. https://doi.org/10.1016/j.ijnss.2020.04.009 